\title{
Lung function eight years after neonatal ventilation
}

\author{
B ANDREASSON, ${ }^{*}$ M LINDROTH, ${ }^{*}$ W MORTENSSON,$\dagger \mathrm{N}$ W SVENNINGSEN, ${ }^{*}$ \\ AND B JONSON $\ddagger$ \\ Neonatal Intensive Care Unit, Departments of *Paediatrics and $¥$ Clinical Physiology, University Hospital, \\ Lund, and †Department of Paediatric Radiology, St Göran's Hospital, Stockholm, Sweden
}

SUMMARY Forty children who had had artificial ventilation during the neonatal period were studied at the age of 8-10 years with spirometry, the nitrogen washout test, bicycle exercise test, pulse oximetry, electrocardiogram, vectorcardiogram, and chest radiography. The median gestational age at birth was 29 weeks, and the median birth weight was $1310 \mathrm{~g}$. Hyaline membrane disease was the indication for neonatal ventilation in 25 children. Bronchopulmonary dysplasia was diagnosed from radiographs in 11 infants $(27 \%)$.

Airway obstruction was observed in 10 of 11 children who had had bronchopulmonary dysplasia and in nine of 29 children who had not. After inhalation of terbutaline, the forced expiratory volume in one second $\left(\mathrm{FEV}_{1}\right)$ was significantly increased. General hyperinflation was found in 16 of 17 children with abnormal chest radiographs (eight who had had bronchopulmonary dysplasia and nine who had not). Functional residual capacity was significantly higher in children with abnormal radiographs. Each child had a normal maximum working capacity and a normal electrocardiogram, and all but two had normal vectorcardiograms. Oxygen saturation at maximum work load decreased significantly in both groups of children. The risk of future respiratory problems calls for further follow up of lung function and chest radiography.

The long term effects on pulmonary function of ventilation during the neonatal period that have been reported are airways obstruction, bronchial hyper-reactivity, hyperinflation, and oxygen desaturation at maximum work load. ${ }^{1-6}$ In our longitudinal follow up studies of preterm infants we have reported persistent radiographic lung abnormalities at 6 years of age in 10 of 14 children who had bronchopulmonary dysplasia as neonates. ${ }^{7}$ When the children were old enough to cooperate satisfactorily in extended lung function studies (that is, at 8-10 years of age), we performed the present study that was designed to evaluate the long term association between ventilation of preterm infants in the neonatal period and later pulmonary function, chest radiography, and electrocardiography.

\section{Patients and methods}

During a two and a half year period 48 preterm infants weighing below $2500 \mathrm{~g}$ at birth survived neonatal diseases after treatment with pressure generated ventilation through a nasotracheal tube.
The results of respiratory function tests carried out during infancy and at the age of 6 years have previously been reported. ${ }^{78}$ One of the children died of the sudden infant death syndrome, four moved from the region, two refused to enter the present follow up study, and one could not do the tests because of tetraplegia. Clinical data on the remaining 40 children are shown in table $1 .{ }^{9}$

In the previous studies ${ }^{7} 8$ the infants were divided into three groups based on the radiological findings soon after they were taken off the ventilators: normal; mild interstitial parenchymal abnormalities; and, bronchopulmonary dysplasia stages III or IV according to the classification of Northway. ${ }^{10}$ In the present study the first two groups have been combined as group 1, and the third group becomes group 2. Bronchial asthma was present in other members of the families of two children in group 2 and four in group 1. There were habitual smokers in the families of five children in group 2 and 21 in group 1.

Lung function studies included vital capacity (VC) and forced expiratory volume in one second $\left(\mathrm{FEV}_{1}\right)$, 
Table 1 Clinical data about the children studied

\begin{tabular}{|c|c|c|c|c|}
\hline & $\begin{array}{l}\text { Children in } \\
\text { group } 1 \\
(n=29)\end{array}$ & $\begin{array}{l}\text { Children in } \\
\text { group } 2 \\
(n=11)\end{array}$ & p Value* & $\begin{array}{l}\text { Group tested } \\
\text { with terbutaline } \\
(n=16)\end{array}$ \\
\hline Boys:girls & $13: 16$ & $5: 6$ & NS & $6: 10$ \\
\hline Median (range) birth weight (g) & $1380(800-2480)$ & $1030(780-1400)$ & 0.009 & $1180(780-2480)$ \\
\hline Median (range) gestational age (weeks) & $29(26-36)$ & $28(25-30)$ & 0.05 & $28(25-33)$ \\
\hline neonatal period & 16 & 9 & NS & 11 \\
\hline No with recurrent apnoea in neonatal period & 7 & 2 & NS & 4 \\
\hline No with other disorders in neonatal period & 6 & 0 & & 1 \\
\hline Median (range) time spent on ventilator (days) & $6(2-72)$ & $29(13-59)$ & $<0.001$ & $22(3-72)$ \\
\hline Median (range) age at follow up (years) & $9 \cdot 2(8 \cdot 3-10 \cdot 3)$ & $8 \cdot 6(8 \cdot 2-10 \cdot 0)$ & NS & $8 \cdot 7(8 \cdot 2-10 \cdot 0)$ \\
\hline $\begin{array}{l}\text { Median (range) standard deviation in height from } \\
\text { predicted value for normal Swedish children }\end{array}$ & $-0.3(-3.0$ to $3 \cdot 0)$ & $-0.5(-1.9$ to 0.8$)$ & NS & $-0 \cdot 1(-3 \cdot 0$ to $3 \cdot 0)$ \\
\hline $\begin{array}{l}\text { Median (range) standard deviation in weight from } \\
\text { predicted value for normal Swedish children }\end{array}$ & $0(-2.5$ to 2.9$)$ & $-0.3(-1.3$ to 1.2$)$ & NS & $-0 \cdot 1(-2 \cdot 5$ to $2 \cdot 9)$ \\
\hline
\end{tabular}

*Statistical analysis by Mann-Whitney $U$ test.

which were measured with a Bernstein spirometer, and functional residual capacity (FRC), which was measured by the nitrogen washout method.

A progressive exercise tolerance test was carried out on a bicycle ergometer (Siemens Elema AB) according to the method of Godfrey et al. ${ }^{11}$ The initial workload, $20-30 \mathrm{~W}$ depending on height, was increased by 10-15 W/minute until exhaustion. The electrocardiogram was recorded continuously. Oxygen saturation was measured in 33 children by pulse oximetry, and in 15 the signal was recorded on paper (Ohmeda Biox 3700 Pulse Oximeter).

Blood pressure, an electrocardiogram, and a vectorcardiogram $^{12}$ were recorded at rest in all children. The lung radiographs were taken in all children, except two who refused to participate. Radiographs were interpreted without knowledge either of clinical data or of the results of the lung function tests.

At a second visit the effects of a $\beta_{2}$ stimulating drug were tested in 16 of 20 children who were in group 2, or who had abnormal spirometry, or both (table 1). Four $0.5 \mathrm{mg}$ doses of terbutaline were inhaled through a spacer at one minute intervals. $\mathrm{FEV}_{1}, \mathrm{VC}$, and FRC were measured before and 10 minutes after the inhalations.

Most data are presented as percentages of predicted values based on actual height. ${ }^{11} 13$ Blood pressure at rest above the 97.5 centile was considered abnormal. ${ }^{14}$

For statistical analysis we used the Mann-Whitney $\mathrm{U}$ test, the Wilcoxon matched pairs signed rank test, Fisher's exact test, and the Spearman rank order correlation coefficient (rs) test, all two tailed. Manual correction was made for ties of the Wilcoxon matched pairs test.
The study was approved by the ethics committee of Lund University, and informed consent was obtained from the parents for the participation of each child.

\section{Results}

CLINICAL DATA

Children in group 2 had lower birth weights, lower gestational ages, and longer periods of ventilation than the children in group 1 (table 1). The two groups did not differ in age, height, or weight at follow up.

Children with abnormal chest radiographs at follow up had been ventilated for longer than those with normal radiographs $(p=0.002)$. The duration of ventilation for all children correlated with $\mathrm{FEV}_{1}$ $(\mathrm{r} s=-0.33, \mathrm{p}=0.04)$ and $\mathrm{VC}(\mathrm{r} s=-0.35, \mathrm{p}=0.04)$. The correlations between gestational age and birth weight and $F E V_{1}$ or VC did not reach significance, though gestational age and birth weight had been significantly lower in children who had abnormal chest radiographs at follow up ( $p=0.04$ and $p=0.02$, respectively). There was no significant association between any respiratory function variable measured in the neonatal period and variables measured at follow up.

\section{LUNG FUNCTION AND EXERCISE TESTING}

$\mathrm{FEV}_{1}, \mathrm{FEV}_{1}: \mathrm{VC}$, and FRC differed significantly from predicted values in both groups of children (table 2). The same variables were more abnormal among children in group 2 than children in group 1 (fig 1). Only one child in group 2 had normal spirometry. Abnormal $\mathrm{FEV}_{1}, \mathrm{FEV}_{1}: \mathrm{VC}$, or both, were found in 12 girls and seven boys, including 10 
Table 2 Lung function tests

\begin{tabular}{|c|c|c|c|c|}
\hline & $\begin{array}{l}\text { Children in group } 1 \\
(n=29)\end{array}$ & $\begin{array}{l}\text { Children in group } 2 \\
(n=11)\end{array}$ & p Value ${ }^{*}$ & $\begin{array}{l}\text { Group tested with } \\
\text { terbutaline }(n=16)\end{array}$ \\
\hline Median $\%$ of predicted $\mathrm{FEV}_{1}{ }^{13}$ & $90 \dagger$ & $75 \dagger$ & 0.004 & 73 \\
\hline Median FEV 1 :VC (\%) & $81 \dagger$ & $74 \dagger$ & 0.002 & 75 \\
\hline Median $\%$ of predicted VC & 101 & 94 & 0.07 & 90 \\
\hline Median $\%$ of predicted FRC & $121 \dagger \ddagger$ & $147+$ & 0.06 & 139 \\
\hline \multirow{2}{*}{$\begin{array}{l}\text { Median } \% \text { of predicted } \\
\text { maximum working capacity }\end{array}$} & & & & \\
\hline & $130 \dagger$ & $134 \dagger$ & NS & 127 \\
\hline
\end{tabular}

*Statistical analysis by Mann-Whitney U test; †statistical analysis of Wilcoxon matched pairs signed rank test-difference between actual and predicted values $\mathrm{p}<0.005 ; \ddagger \mathrm{n}=28$.

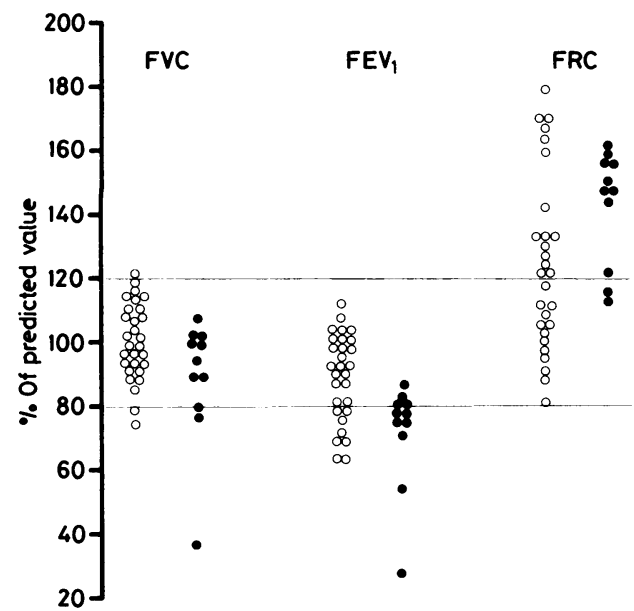

Fig 1 Lung function 8-10years laterinchildren whohad been on ventilators as neonates. $V C, F E V_{1}$, and FRCfor each patient are expressed as percentages of values predicted for height. ${ }^{13}$ Open circles denote children in group 1, solid circles those ingroup 2.

of 11 in group $2 . \mathrm{FEV}_{1}$ correlated with $\mathrm{VC}(\mathrm{rs}=0 \cdot 78$, $\mathrm{p}<0.001$ ), but not with FRC, or with oxygen saturation.

All children performed a normal maximum work load. The mean heart rate at maximum exercise was 184 /minute, though three failed to reach a heart rate of $170 /$ minute. There was no significant change in $\mathrm{FEV}_{1}$ after work to exhaustion, in either group.

Oxygen saturation during work was significantly lower in both group $2(\mathrm{p}=0.009)$ and group 1 $(p=0.0004)$, with a decrease of more than $4 \%$ in 11 of the 31 children tested (fig 2). Oxygen saturation was less than $95 \%$ during maximal exercise in 16 children; in two it was below $96 \%$ at rest (93 and $90.5 \%$, respectively), decreasing during work to 90 and $84 \%$, respectively. In all children, oxygen saturation increased again after exercise towards the pretest value, which was reached within four minutes in 11 of 18 children.

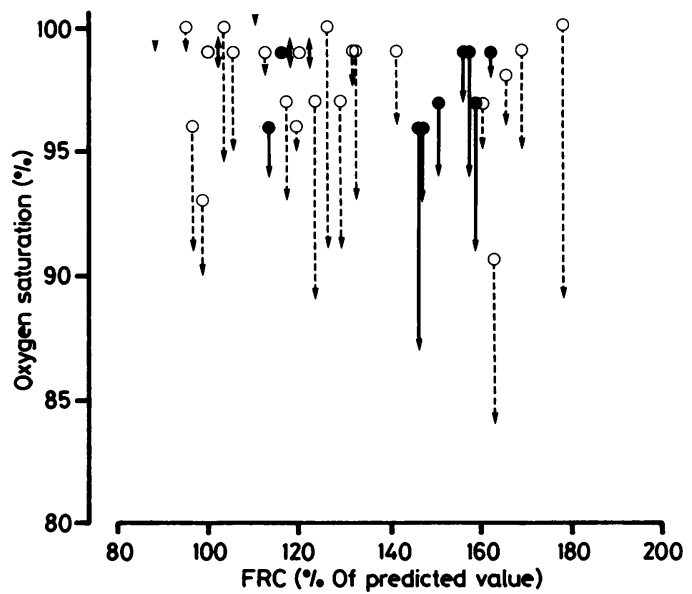

Fig2 Oxygen saturationat restand during maximum work load and FRC. Open circles and broken lines denote children in group 1, and solid circles and thick lines those in group 2. Arrows show maximum workload.

\section{$\beta$ SYMPATHOMIMETICS}

After terbutaline inhalation $\mathrm{FEV}_{1}$ increased significantly $(p=0 \cdot 008)($ table 3$)$. In five children in group 2 and four in group 1 the increase was over $10 \%$. A

Table 3 Change in the spirometric and lung volume reversibility effect of terbutaline 10 minutes after inhalation of $2 \mathrm{mg}$ terbutaline in 16 children with BPD, impaired spirometry, or both

\begin{tabular}{lcll}
\hline Measurement & $\%$ Change & \multirow{2}{*}{$p$ Value $^{*}$} \\
\cline { 2 - 3 } & Median & Range & \\
\hline FEV $_{1}$ & 13 & -6 to 33 & 0.008 \\
FEV $_{1}$ :VC & 11 & -6 to 32 & 0.001 \\
VC & 0 & -5 to 19 & NS \\
FRC & -3 & -22 to 20 & 0.05
\end{tabular}

*Significance of differences before and after inhalation assessed by Wilcoxon matched pairs signed rank test. 
decrease of FRC was noted in 14 of 16 children, but mean $\mathrm{VC}$ remained unchanged.

\section{CHEST RADIOGRAPHY}

Chest radiographs were abnormal in 17 (eight in group 2 and nine in group 1) of the 38 children examined (table 4). Abnormal pulmonary radiographs were significantly more frequent among children who had had abnormal radiographs just after they had been ventilated $(p<0 \cdot 001)$. No cardiovascular abnormalities were found. Perihilar fibrosis was mild and had decreased during the four years preceding this study. Sixteen of 17 children with abnormal radiographs at this follow up had generalised hyperinflation (table 4). Four children in group 2 also had local areas of accentuated hyperinflation. In six children the degree of hyperinflation had increased during the four years preceding this study. FRC was above two standard deviations in 15 children, being higher in children with abnormal chest radiographs at follow up than in those with normal radiographs $(p=0 \cdot 04)$. FRC was more often above $140 \%$ of the predicted value in children in group 2 than in those in group 1 $(p=0 \cdot 02)$.

\section{CARDIAC EXAMINATION}

All children had normal electrocardiograms, both at rest and during exercise. Two children in group 2 had vectorcardiographic signs of right ventricular hypertrophy. After initial ventilator treatment for 24 and 58 days, respectively, they had extremely high respiratory resistance. One of them still had abnormal resistance at 1 year of age, but only slightly impaired lung function at 8 years of age (VC $89 \%, \mathrm{FEV}_{1} 79 \%$, and FRC $113 \%$ of predicted values). The other one had normal respiratory resistance at 2 years of age but lung function had deteriorated by 9 years of age $\left(\mathrm{VC} 75 \%^{2}, \mathrm{FEV}_{1} 61 \%\right.$, and FRC $150 \%$ of predicted values). Mild hypertension (145/70) was diagnosed in one boy with unilateral renal agenesis, but all the other children had normal blood pressure at rest.

CLINICAL RESPIRATORY PROBLEMS

Six children, two in group 2 , were treated with a $\beta_{2}$ stimulant during respiratory tract infections. After 4 years of age, one boy had been treated for pneumonia twice, and two children had been admitted to hospital for respiratory disorders-one once, the other twice. In one of them, a girl in group 2 , histological examination of a biopsy specimen of nasal mucosa was compatible with the immotile cilia syndrome; she had persistent respiratory problems and deteriorated lung function (VC $35 \%$ and $\mathrm{FEV}_{1}$ $29 \%$ of predicted value).

\section{Discussion}

In our longitudinal follow up studies of preterm infants who had to be treated with artificial ventilation, we have shown that there is high respiratory resistance and low compliance in infancy after babies have been taken off the ventilators. ${ }^{8}$ Most abnormal findings were found in infants in group 2 . During the first two years the compliance normalised in all children, while resistance remained abnormal in half the children in group 2. Until 2 years of age bronchitis was frequent in children who had been treated on ventilators for more than two weeks, and especially in the children in group $2 .{ }^{7} \mathrm{At}$ 4-6 years of age, chest radiographs showed interstitial fibrosis and local areas of hyperinflation, again predominately in children in group 2 . This follow up investigation at 8 to 10 years of age shows airway obstruction with general hyperinflation measured as abnormal FRC, and seen on chest radiographs.

The airway obstruction and hyperinflation seen in our children are similar to those seen in earlier studies of preterm infants treated with artificial ventilation and followed up at more than 5 years of age (Rutishauser $M$ and Hug-Batscheler H. Presented at European Paediatric Respiratory Society VI meeting, Helsinki, 1987). ${ }^{13-5}$ 15-17 In some studies, in which the children examined had been more mature at birth, such abnormalities were either less pronounced ${ }^{2} 18-20$ or did not differ from those in premature children born without lung disease. ${ }^{4} 621$

Confirming other reports, ${ }^{17-20}$ the radiographs showed mild fibrosis and local hyperinflation. The predominant general hyperinflation found in our

Table 4 Comparison between results of chest radiography in the neonatal period and those at 8-10 years of age

\begin{tabular}{lrlc}
\hline $\begin{array}{l}\text { Findings in the neonatal period } \\
\text { after the child had been ventilated }\end{array}$ & No of children & Findings at 8-10 years of age \\
\cline { 3 - 4 } & & Normal & Fibrosis \\
\hline Normal & 20 & Hyperinflation \\
Mild interstitial abnormalities & $8\}$ (group 1) & 17 & 0 \\
BPD stages III and IV & 10 (group 2) & 2 & 1 \\
\hline
\end{tabular}


patients has previously been reported in three preterm children aged 3 to 5 years. ${ }^{22}$ It has also previously been seen in a long term follow up of children who had had tracheostomies during the first year of life. ${ }^{23}$ The higher FRC seen in our children with hyperinflation emphasises the significance of this radiographic observation.

In contrast to our findings in group 2, signs of right ventricular hypertrophy have previously been reported in $30-70 \%$ of children with bronchopulmonary dysplasia. 51724

The effects of $\beta_{2}$ sympathomimetic drugs have previously been reported to vary in children with bronchopulmonary dysplasia ${ }^{35}$ but we noted a positive effect in patients with bronchopulmonary dysplasia or abnormal spirometry, or both.

The observed super normal maximum working capacity probably represents normal maximum working capacity. According to our experiences of routine progressive exercise tests, Swedish children today exceed the normal values of British children 20 years ago. ${ }^{11}$ Although lung function and chest radiographs were more abnormal in children in group 2 than in group 1 , the maximum working capacity did not differ between the two groups. The significant decrease in oxygen saturation during exercise in both groups was similar to that observed by others. ${ }^{19}{ }^{25}$ Further interpretation of our results will require additional studies.

The absence of exercise induced bronchospasm in our children differs from the results of other investigators, who reported exercise induced bronchospasm in children with bronchopulmonary dysplasia ${ }^{1}$ as well as bronchial hyper-reactivity diagnosed with metacholine or histamine tests (Rutishauser M and Hug-Batschelet H. Presented at European Paediatric Respiratory Society VI Meeting, Helsinki, 1987). ${ }^{2}$

Contrary to the report of Nickerson and Taussig, ${ }^{26}$ but in agreement with Gerhardt et al, ${ }^{27}$ we found no correlation between bronchopulmonary dysplasia and family history of asthma. Our figures were the same as those reported by Riedel ${ }^{2}$ in children with bronchopulmonary dysplasia but lower than that observed by Stahlman et al among children with hyaline membrane disease. ${ }^{18}$

In the children in our study the incidence of abnormal chest radiographs shortly after they had been taken off ventilators, ${ }^{78}$ was associated with the occurrence of abnormal chest radiographs at follow up. It seems that the frequency of late radiographic changes are as common in the group of infants with initially mild interstitial abnormalities as in those with bronchopulmonary dysplasia. Our observations correspond to other reports in that we are able to correlate the length of time spent on the ventilator and the occurrence of an abnormal chest radiograph, and a low $\mathrm{FEV}_{1}$ at late follow up (Rutishauser $\mathrm{M}$ and Hug-Batschelet $\mathrm{H}$. Presented at European Paediatric Respiratory Society VI Meeting, Helsinki, 1987). ${ }^{18}$ Radiographic changes at follow up also correlated with low birth weight and low gestational age.

Previously only one group has reported an association between neonatal and late lung functionthat is, the development of severe airway obstruction at 9 years of age in three children with large FRC and low compliance in infancy. ${ }^{5}$ We found high respiratory resistance in the neonatal period and persisting airway obstruction at 8 to 10 years in our children with both mild and severe neonatal lung disease. These observations support previous suggestions that not only degree of prematurity and severity of neonatal lung disease but also duration and probably mode of treatment by ventilator contribute to impaired airway development. ${ }^{628}$

In conclusion, most of our children had no regular respiratory disorders at 8 to 10 years of age. Our findings of airway obstruction, hyperinflation, and impaired oxygenation during exercise, however, as possible long term effects of neonatal ventilation, may imply a certain risk of future respiratory dysfunction. We therefore plan a pulmonary function and radiographic follow up of the same series in the teenage period. The beneficial effect of $\beta_{2}$ sympathomimetics on airway obstruction suggests bronchodilator treatment to be an alternative worth consideration during airway infection.

The work was supported by the Swedish Medical Research Council (grants 4732 and 02872), the Swedish National Association against Chest and Heart Diseases, "Stiftelsen Samariten", "Stiftelsen Allmänna BB:s Minnesfond" and "Förenade Liv" Mutual Group Life Insurance Company, Stockholm, Sweden.

\section{References}

${ }^{1}$ Bader D, Ramos AD, Lew CD, Platzker ACG, Stabile MW, Keens TG. Childhood sequelae of infant lung disease: exercise and pulmonary function abnormalities after bronchopulmonary dysplasia. J Pediatr 1987;110:693-9.

2 Riedel F. Long term effects of artificial ventilation in neonates. Acta Paediatr Scand 1987;76:24-9.

${ }^{3}$ Berman W, Katz R, Yabek SM, Dillon T, Fripp RR, Papile L-A. Long-term follow up of bronchopulmonary dysplasia. $J$ Pediatr 1986;109:45-50.

${ }^{4}$ Bertrand J-M, Riley SP, Popkin J, Coates AL. The long-term pulmonary sequelae of prematurity: the role of familial airway hyper-reactivity and the respiratory distress syndrome. $N$ Engl $J$ Med 1985;312:742-5.

5 Smyth JA, Tabachnik E, Duncan WJ, Reilly BJ, Levison H. Pulmonary function and bronchial hyperreactivity in long-term survivors of bronchopulmonary dysplasia. Pediatrics 1981;68: 336-40.

6 Coates AL, Bergsteinsson H, Desmond K, Outerbridge EW, Beaudry PH. Long-term pulmonary sequelae of premature birth with and without idiopathic respiratory distress syndrome. J Pediatr 1977;90:611-6. 
${ }^{7}$ Lindroth M, Mortensson W. Long-term follow-up of ventilator treated low birthweight infants. I. Chest X-ray, pulmonary mechanics, clinical lung disease and growth. Acta Paediatr Scand 1986;75:819-26.

${ }^{8}$ Lindroth M, Jonson B, Svenningsen NW, Mortensson W. Pulmonary mechanics, chest X-ray and lung disease after mechanical ventilation in low birthweight infants. Acta Paediatr Scand 1980;69:761-70.

9 Karlberg P, Taranger J, Engström I, et al. I Physical growth from birth to 16 years and longitudinal outcome of the study during the same age period. Acta Paediatr Scand 1976;65(suppl 258):7-76.

${ }^{10}$ Northway WH, Rosan RC, Porter DY. Pulmonary disease following respiratory therapy of hyaline-membrane disease. $N$ Engl J Med 1967;276:357-68.

$"$ Godfrey S, Davies CTM, Wozniak E, Barnes CA. Cardiorespiratory response to exercise in normal children. Clin Sci 1971;40:419-31.

12 Jonson B, Almquist L-O, Edenbrandt L, Lundh B, Niklason L, Pahlm O. High quality vectorcardiography. In: Proceedings of computers in cardiology, September 88-11, 1985, Linköping, Sweden. Washington: Institute of Electrical and Electronics Engineers, 1985:163-6.

13 Polgar G, Promadhat V. Pulmonary function testing in children: techniques and standards. Philadelphia: WB Saunders, 1971.

${ }^{14}$ Blumenthal S, Epps RP, Heavenrich R, et al. Report of the task force on blood pressure control in children. Pediatrics 1977; 59(suppl):797-804.

15 Wheeler WB, Castile RG, Brown ER, Wohl MEB. Pulmonary function in survivors of prematurity. Am Rev Respir Dis 1984;129:218.

${ }^{16}$ Borkenstein J, Borkenstein M, Rosegger H. Pulmonary function studies in long-term survivors with artificial ventilation in the neonatal period. Acta Paediatr Scand 1980;69:159-63.

17 Johnson JD, Malachowski NC, Grobstein R, Welsh D, Daily WJR, Sunshine P. Prognosis of children surving with the aid of mechanical ventilation in the newborn period. J Pediatr 1974;84: 272-6.
18 Stahlman M, Hedvall G, Lindström D, Snell J. Role of hyaline membrane disease in production of later childhood lung abnormalities. Pediatrics 1982;69:572-6.

19 Heldt GP, Mcllroy MB, Hansen TN, Tooley WH. Exercise performance of the survivors of hyaline membrane disease. J Pediatr 1980;96:995-9.

${ }^{20}$ Lamarre A, Linsao L, Reilly BJ, Swyer PR, Levison H. Residual pulmonary abnormalities in survivors of idiopathic respiratory distress syndrome. Am Rev Respir Dis 1973;108: 56-61.

${ }^{21}$ Mansell AL, Driscoll JM, James LS. Pulmonary follow-up of moderately low birth weight infants with and without respiratory distress syndrome. J Pediatr 1987;110:111-5.

${ }^{22}$ Shepard FM, Johnston RB, Klatte EC, Burko H, Stahlman M. Residual pulmonary findings in clinical hyaline-membrane disease. $N$ Engl J Med 1968;279:1063-71.

${ }^{23}$ Haglund G, Bjure J, Claesson I, et al. Long-term follow-up of infants under intensive care with tracheotomy during the period 1956-1965. Acta Anaesthesiol Scand 1984;28:166-73.

${ }^{24}$ Harrod JR, L'Heureux P, Wangensteen OD, Hunt CE. Longterm follow-up of severe respiratory distress syndrome treated with IPPB. J Pediatr 1974;84:277-86.

${ }^{25}$ Sheller J, Lucht W, Goel A, Snell J, Stahlman M. Pulmonary function in long term survivors of hyaline membrane disease. Am Rev Respir Dis 1986;133:154.

${ }^{26}$ Nickerson BG, Taussig LM. Family history of asthma in infants with bronchopulmonary dysplasia. Pediatrics 1980;65:1140-4.

${ }^{27}$ Gerhardt T, Hehre D, Feller R, Reifenberg L, Bancalari E. Serial determination of pulmonary function in infants with chronic lung disease. $J$ Pediatr 1987;110:448-56.

${ }^{28}$ Tepper RS, Morgan WJ, Cota K, Taussig LM. Expiratory flow limitation in infants with bronchopulmonary dysplasia. J Pediatr 1986;109:1040-6.

Correspondence to Dr Bengt Andréasson, Department of Paediatrics, University Hospital, S-221 85 Lund, Sweden.

Accepted 5 July 1988 